\title{
Lactate promotes specific differentiation in bovine granulosa cells depending on lactate uptake thus mimicking an early post-LH stage
}

\author{
Anja Baufeld and Jens Vanselow ${ }^{*}$ (D)
}

\begin{abstract}
Background: The LH-induced folliculo-luteal transformation is connected with alterations of the gene expression profile in cells of the granulosa layer. It has been described that hypoxic conditions occur during luteinization, thus favoring the formation of L-lactate within the follicle. Despite being a product of anaerobic respiration, L-lactate has been shown to act as a signaling molecule affecting gene expression in neuronal cells. During the present study, we tested the hypothesis that L-lactate may influence differentiation of follicular granulosa cells (GC).

Methods: In a bovine granulosa cell culture model effects of L- and D-lactate, of increased glucose concentrations and of the lactate transport inhibitor UK5099 were analyzed. Steroid hormone production was analyzed by RIA and the abundance of key transcripts was determined by quantitative real-time RT-PCR.

Results: L-lactate decreased the production of estradiol and significantly affected selected genes of the folliculo-luteal transition as well as genes of the lactate metabolism. CYP19A1, FSHR, LHCGR were down-regulated, whereas RGS2, VNN2, PTX3, LDHA and lactate transporters were up-regulated. These effects could be partly or completely reversed by pre-treatment of the cells with UK5099. The non-metabolized enantiomer D-lactate had even more pronounced effects on gene expression, whereas increased glucose concentrations did not affect transcript abundance.

Conclusions: In summary, our data suggest that L-lactate specifically alters physiological and molecular characteristics of GC. These effects critically depend on L-lactate uptake, but are not triggered by increased energy supply. Further, we could show that L-lactate has a positive feedback on the lactate metabolism. Therefore, we hypothesize that L-lactate acts as a signaling molecule in bovine and possibly other monovular species supporting differentiation during the folliculo-luteal transformation.
\end{abstract}

Keywords: Bovine, Granulosa cells, L-lactate, Expression

\section{Background}

The pre-ovulatory LH surge induces massive changes within the follicle, including morphological, physiological and molecular alterations $[1,2]$. The reorganization of the follicle is accompanied by a tremendous shift of the gene expression profile particularly in cells of the granulosa layer [3, 4]. The aromatase-encoding gene CYP19A1, and the gonadotropin receptors, FSHR and LHCGR, are significantly down-regulated immediately after the

\footnotetext{
* Correspondence: vanselow@fbn-dummerstorf.de

Institute of Reproductive Biology, Leibniz Institute for Farm Animal Biology (FBN), Wilhelm-Stahl-Allee 2, 18196 Dummerstorf, Germany
}

pre-ovulatory LH surge in vivo $[5,6]$. In contrast, $R G S 2$, encoding the regulator of $\mathrm{G}$ protein signaling 2 , and the inflammatory-related genes $V N N 2$, encoding the vascular non-inflammatory molecule 2 , and PTX3, encoding pentraxin 3 , were highly up-regulated $[4,7,8]$. It was hypothesized that hypoxic conditions occur during folliculogenesis and support ovulation $[9,10]$. However, it is still unclear whether hypoxia is an essential signal during the folliculo-luteal transition [11]. As for granulosa cells (GC) it was proposed that pericellular hypoxia present under high cell density conditions may induce differentiation [12]. Likewise, 
we showed that high cell density induces specific changes of the gene expression and steroid hormone profiles in cultured GC mimicking an early post-LH status of GC differentiation [13]. Furthermore, applying a whole-genome approach we could demonstrate in GC cultured at high plating density, that genes connected to hypoxia are affected [14]. In particular $L D H A$ transcripts encoding L-lactate dehydrogenase were remarkably up-regulated. It was demonstrated also by others that $L D H A$ expression is regulated by hypoxia [15]. In addition, a binding site for HIF $1 / 2 \alpha$ could be identified in the $L D H A$ promotor explaining the hypoxia-related expression $[16,17]$. On the other hand Lee et al. [18] proposed a HIF-independent mechanism of lactate accumulation under hypoxic conditions. Hence, L-lactate might play a role during the folliculo-luteal transition. Reports from different species demonstrated higher L-lactate concentrations within the follicular fluid than in the respective serum, ranging from $6 \mathrm{mM}$ in human up to $27 \mathrm{mM}$ in rats [19-21]. Generated even during adequate oxygen provision L-lactate might represent an important regulator of metabolism [22]. A study in L6 cells revealed that L-lactate may be involved in the delivery of oxidative and gluconeogenic substrates thus leading to the cell-cell and intracellular lactate shuttle hypothesis $[23,24]$. In this context L-lactate is also described as a metabolic signal. L-lactate affects its own metabolism by stimulating the expression of the lactate transporter MCT1 in rat muscle cells [25]. In mouse granulosa cells MCTs were identified regulating the transport of L-lactate within the female reproductive tract [26]. Moreover, in neuronal cells L-lactate affects the expression of genes linked to neuronal plasticity during establishment of the longterm memory [27, 28]. In this study we therefore tested the hypothesis that L-lactate is a signaling molecule in the bovine follicle. To that end, we analyzed the effects of L-lactate in a serum-free estradiol (E2)-producing GC culture model $[13,29,30]$ on specific morphological, physiological and molecular parameters.

\section{Methods}

\section{Tissue collection and cell culture}

Bovine ovaries were obtained from a local abattoir and transported in cold $1 \times$ PBS containing penicillin (100 IU), streptomycin $(0.1 \mathrm{mg} / \mathrm{ml})$ and amphotericin $(0.5 \mu \mathrm{g} / \mu \mathrm{l})$. By aspirating small to medium sized follicle $(<6 \mathrm{~mm})$ with a syringe and $18 \mathrm{G}$ needle a nearly pure population of granulosa cells was recovered [5]. GC were collected in 1× PBS (with antibiotics) and pooled from 30 to 50 ovaries with 15 to 30 follicles per ovary. Accordingly, samples from at least 15 different cows with nondefined cyclicity status were included in each preparation.
To determine the amount of living cells GC were counted in a hemocytometer by trypan blue exclusion method and cryo-preserved in freezing media (fetal calf serum containing 10\% DMSO; Roth, Karlsruhe, Germany). The cryopreserving procedure did not alter general characteristics of GC in culture as we could detect equal levels of marker gene expression as compared with cultures from freshly isolated GC (Additional file 1: Figure S1). All experiments were performed in technical and biological replicates (at least 3) using different cell preparations. Shortly before the onset of cell culture 24-well plates were coated with collagen R (0.02\%; Serva, Heidelberg, Germany) to improve the cell attachment [13]. Frozen GC were immediately separated from the freezing media by centrifugation (500 $\times \mathrm{g}$ for $3 \mathrm{~min}$ ) and re-suspended in culture media with supplements as described previously [13]. Briefly, cells of a total cell number of $1.0 \times 10^{5}$ cells/well were cultured under serum-free conditions in $\alpha$-MEM containing L-Glutamin $(2 \mathrm{mM})$, sodium bicarbonate $(0.084 \%)$, BSA (0.1\%), HEPES $(20 \mathrm{mM})$, sodium selenite $(4 \mathrm{ng} / \mathrm{ml})$, transferrin $(5 \mu \mathrm{g} / \mathrm{ml})$, insulin $(10 \mathrm{ng} / \mathrm{ml})$, non-essential amino acids $(1 \mathrm{mM})$, penicillin $(100 \mathrm{IU} / \mathrm{ml})$ and streptomycin $(0.1 \mathrm{mg} / \mathrm{ml})$, FSH $(20 \mathrm{ng} / \mathrm{ml}$; Sigma Aldrich, Steinheim, Germany), $\mathrm{R}^{3}$ IGF-1 (50 ng/ml; Sigma Aldrich), and androstenedione ( $2 \mu \mathrm{M}$; Sigma Aldrich). The cells were additionally treated over the complete culture period with sodium L-lactate $(7.5 \mathrm{mM}-30 \mathrm{mM})$, D-lactate $(30 \mathrm{mM}$, both Sigma-Aldrich), or sodium chloride as vehicle control (7.5 mM - $30 \mathrm{mM}$; Sigma Aldrich). For inhibitory studies cells were initially pre-treated with inhibitor UK5099 (50 $\mu \mathrm{M}$; Sigma Aldrich) for $48 \mathrm{~h}$ and subsequently treated with L-lactate or the vehicle control. The L-lactate transporters were inhibited with UK5099 (50 $\mu \mathrm{M}$; Sigma Aldrich). All reagents were purchased from Merck Millipore (Berlin, Germany) if not stated otherwise. GC were maintained for 8 days at $37{ }^{\circ} \mathrm{C}$ and $5 \% \mathrm{CO}_{2}$ to allow the cells to completely recover from plating stress and to resume E2 production [31]. Two thirds of the spent culture medium was replaced every other day. Also in previous studies it has been repeatedly shown that GC obtained from small follicles $(<6 \mathrm{~mm})$ require several days in vitro to develop an estradiol-active status that mimics the in vivo GC state shortly before the LH surge $[13,32]$.

\section{Measurements of cell viability and hormone production}

The cell viability test was performed using the CellTiter 96 AQueous One Solution Cell Proliferation Assay (Promega, Mannheim, Germany). The one compound solution contains a MTS tetrazolium salt which is converted into a colored formazan product by $\mathrm{NAD}(\mathrm{P}) \mathrm{H}$ that is only present in viable cells. Therefore, the quantitative detection of the formazan product by absorbance measurement represents the number of viable cells in culture. The assay was performed according to the manufacturer's 
protocol. Therefore, cells were cultured in collagen $R$ coated 96-well plates. The absorbance was measured in a 96-well plate reader (FLUOstar Omega, BMG Labtech, Ortenberg, Germany) at a wavelength of $490 \mathrm{~nm}$. Progesterone (P4) and E2 concentrations were measured using competitive ${ }^{3} \mathrm{H}$-radioimmunoassay (RIA) as described previously [33]. For $\mathrm{P} 4$ the tracer $[1,2,6,7-3 \mathrm{H}(\mathrm{N})]$ progesterone was purchased from PerkinElmer (Boston, USA) and the E2 tracer [2,4,6,7-3H]estradiol-17 $\beta$ was purchased from GE Healthcare (Freiburg, Germany). Radioactivity measurement was performed in a liquid scintillation counter (LSC) with an integrated RIA-calculation program (TriCarb 2900 TR, PerkinElmer) and the intra- and interassay coefficients of variation (CV) for P4 were specified as $7.6 \%$ and $9.8 \%$, whereas for E2 intra- and interassay CV were $6.9 \%$ and $9.9 \%$, respectively. For analysis the cell culture media was diluted 1:40 in RIA-buffer for P4 measurement and was used undiluted for E2 and measured in duplicates.

\section{RNA preparation, cDNA synthesis and quantitative Real-Time PCR}

Total RNA isolation was performed with the NucleoSpin RNA Kit (Macherey-Nagel, Düren, Germany) following the protocol of the manufacturer and RNA concentration was measured using a NanoDrop 1000 Spectrophotometer (Thermo Scientific, Bonn, Germany). Subsequently, cDNA was synthesized with SensiFAST cDNA Synthesis Kit (Bioline, Luckenwalde, Germany) from 250 ng RNA. Quantitative Real-Time PCR for gene expression analysis was accomplished with SensiFast SYBR No-ROX (Bioline) and gene-specific primers (listed in Table 1). Complementary DNA samples were amplified in duplicate from 0.2 and $0.4 \mu \mathrm{l}$ in a total volume of $12 \mu \mathrm{l}$. The PCR was performed and quantified in a LightCycler 96 instrument (Roche, Mannheim, Germany) with following cycle conditions: pre-incubation at $95{ }^{\circ} \mathrm{C}$ for 5 min, 40 amplification cycles of denaturation at $95^{\circ}$ $\mathrm{C}$ for $20 \mathrm{~s}$, annealing at $60{ }^{\circ} \mathrm{C}$ for $15 \mathrm{~s}$, extension at $72{ }^{\circ} \mathrm{C}$ for $15 \mathrm{~s}$, and a single-point fluorescence acquisition for $10 \mathrm{~s}$. Analysis of the melting point was done immediately afterwards to ensure amplification of correct products. For the same reason the length of PCR products was checked by agarose gel electrophoresis (3\%, ethidium bromide stained). Cloned and sequenced PCR products were used as external standards for absolute quantification. Of these, fresh dilutions were prepared from five different concentrations of standards $\left(5 \times 10^{-12}-5 \times 10^{-16} \mathrm{~g} D N A /\right.$ reaction $)$ and co-amplified in each run. The absolute quantified transcript abundance was normalized to the reference gene $R P L P O$, showing stable expression values throughout the different treatments.

\section{Statistics}

Each experiment was done with at least three biological replicates (different GC preparations) and three technical replicates (different culture wells) each. SigmaPlot 12.0 Statistical Analysis System (Jandel Scientific, San Rafael, CA, USA) was used for statistical analysis. Statistical analysis of hormone and qPCR measurement was carried out with untransformed data. Comparison of two different treatments (e.g. L-lactate vs. vehicle control) was performed with the student $t$-test or Mann-Whitney Test, when the requirements of the t-test were not fulfilled. Multiple comparisons were done with one-way analysis of variance (ANOVA, Holm-Sidak method). Limits of statistical significance were set at $P<0.05$. For graphical presentation the ordinate was scaled in $\log 2$ (except for glucose experiment), which distributes the effects of up- and down-regulation more uniformly.

\section{Results \\ Effects of L- and D-lactate on hormone production and gene expression}

Initially, effects of different L-lactate concentrations on cultured GC were analyzed. Previous studies reported effective concentrations of $20 \mathrm{mM}$ or $30 \mathrm{mM}$ in different cell types [27, 34, 35]. In various species L-lactate concentrations in the antral fluid of growing follicles could be detected between 6 and $27 \mathrm{mM}[19,21]$. Therefore, we treated the GC with L-lactate concentrations ranging from $7.5 \mathrm{mM}$ to $45 \mathrm{mM}$ and corresponding vehicle controls $(\mathrm{NaCl})$. As highly sensitive parameters we determined the abundance of several marker transcripts, which are highly regulated in the GC layer during the folliculo-luteal transition [4]. The treatment with $30 \mathrm{mM}$ and $45 \mathrm{mM}$ L-lactate resulted in considerable changes of these molecular parameters compared to the control (Fig. 1a). We could identify a dose-dependent downregulation of CYP19A1, FSHR and LHCGR. RGS2 and $V N N 2$ transcripts revealed a dose-dependent upregulation. Whereas a significant up-regulation of $R G S 2$ expression was already achieved with $7.5 \mathrm{mM}$ L-lactate, a significant down-regulation of CYP19A1 expression was observed with $30 \mathrm{mM}$ L-lactate. We therefore considered $30 \mathrm{mM}$ L-lactate as an effective concentration during the ongoing study of in vitro cultured GC.

In studies by others D-lactate, a non-metabolized and iso-osmotic enantiomer of L-lactate, was used as a control $[27,36]$. However, in GC the supplementation with D-lactate led to even more pronounced and specific changes of several marker genes (Fig. 1b). The downregulation of CYP19A1, FSHR and LHCGR by D-lactate revealed to be more prominent than with L-lactate. The same effect could be observed for the up-regulation of RGS2 and VNN2. Accordingly, D-lactate could not be used as an appropriate control. 
Table 1 Gene specific primers used in quantitative Real-Time PCR

\begin{tabular}{|c|c|c|c|c|}
\hline Gene & dir & Sequence & Size (bp) & Accession No. \\
\hline \multirow[t]{2}{*}{$R P L P O$} & for & TGGTTACCCAACCGTCGCATCTGTA & 142 & NM_001012682 \\
\hline & rev & CACAAAGGCAGATGGATCAGCCAAG & & \\
\hline \multirow[t]{2}{*}{ CYP19A1 } & for & GCTITTGGAAGTGCTGAACCCAAGG & 172 & NM_174305 \\
\hline & rev & GGGCCCAATTCCCAGAAAGTAGCTG & & \\
\hline \multirow[t]{2}{*}{ FSHR } & for & TCACCAAGCTTCGAGTCATCCCAAA & 189 & NM_174061 \\
\hline & rev & TCTGGAAGGCATCAGGGTCGATGTA & & \\
\hline \multirow[t]{2}{*}{ LHCGR } & for & GCATCCACAAGCTTCCAGATGTTACGA & 205 & NM_174381 \\
\hline & rev & GGGAAATCAGCGTTGTCCCATTGA & & \\
\hline \multirow[t]{2}{*}{ RGS2 } & for & AAGCCCAGCTGTGGTCAGAAGCATT & 127 & NM_001075596 \\
\hline & rev & TCTTCACAGGCCAGCCAGAATTCAA & & \\
\hline \multirow[t]{2}{*}{ VNN2 } & for & TCCCACAGCTTGGATGAACGTTITG & 267 & NM_001163920 \\
\hline & rev & TAGGCACTCCAATTCATGGCTGGTG & & \\
\hline \multirow[t]{2}{*}{ PTX3 } & for & TTTGTGCGCTCTGGTCTGCAGTGT & 164 & NM_001076259 \\
\hline & rev & CATGGTGAAGAGCTTGTCCCACTCG & & \\
\hline \multirow[t]{2}{*}{$\angle D H A$} & for & GGGTTGGTGCTGTTGGCATGGCCT & 232 & NM_174099.2 \\
\hline & rev & TCTCCCTCTTGCTGACGTGCCCCA & & \\
\hline \multirow[t]{2}{*}{ SLC16A1 } & for & GGTGGAGGTCCTATCAGCAGTGTCCT & 236 & NM_001037319.1 \\
\hline & rev & AGTCCATTTGCCAGCGGTCGTCTC & & \\
\hline \multirow[t]{2}{*}{ SLC16A7 } & for & ACCCAGTGCCGGAGACCAGCAGTT & 182 & NM_001076336.2 \\
\hline & rev & GGATGTGGTGGTGGGGTGCCTCCT & & \\
\hline
\end{tabular}

dir, direction; for, forward primer; rev, reverse primer

Further on we analyzed whether L-lactate or the vehicle control $(\mathrm{NaCl})$ compromised the viability of cultured GC. Although the viability tended to be slightly affected in L-lactate treated cells, these effects were not statistically significant (Table 2). As a paradigm for differentiation-specific changes of cultured GC the morphology, hormone concentrations as well as the expression of GC-specific marker genes were analyzed in L-lactate-treated GC. As shown in Fig. 2a and b the morphology of cultured GC was not considerably altered. GC displayed the typical fibroblast-like phenotype with occasional cluster formation under both experimental conditions. In contrast, the estradiol production was clearly affected showing considerably lower concentration (Fig. 2c). Additionally, the abundance of several selected marker transcripts revealed a significant regulation upon L-lactate treatment (Fig. 2d). The abundance of CYP19A1 transcripts encoding the key enzyme of estradiol synthesis, aromatase P450, was significantly lower in L-lactate treated GC than in the controls (dashed line). This is also reflected by the observed decrease of E2 production. Similarly, the amounts of FSHR and LHCGR transcripts were significantly down-regulated. In contrast, RGS2, VNN2 and PTX3 transcripts were considerably up-regulated by L-lactate.

In addition to these long-term effects of L-lactate, we were interested whether a short-term treatment is sufficient to induce these massive physiological and molecular changes. Thus, the cultured GC were treated with $30 \mathrm{mM}$ L-lactate during the final $24 \mathrm{~h}$ of the culture period. Under these conditions no significant alterations of marker transcripts as well as of hormone concentrations could be observed (Table 3). This indicates that L-lactate has only long-term effects on GC differentiation. Additionally, because increased L-lactate concentrations might be used as an additional source of energy by the cultured GC, we analyzed whether an increased energy supply suggestively resulting in higher metabolic activity of the cells, could be responsible for the effects of L-lactate. Therefore we increased the glucose concentration of the basal media from $1 \mathrm{~g} / \mathrm{l}$ up to $4 \mathrm{~g} / \mathrm{l}$. The 4-fold increase of glucose concentration however, did not lead to any changes in the expression of the selected marker genes (Fig. 3).

\section{Effects of specific inhibition of L-lactate transporters}

As a first approach to elucidate molecular mechanisms that are involved in the observed effects of Llactate we pre-treated GC with specific inhibitor of lactate transporters (MCTs). Inhibition of MCTs with UK5099 could partly reverse the L-lactate effect (Figs. 4a and b). Negative effects of L-lactate on E2 production could be abolished (Fig. 4a). The inhibition of MCTs also resulted in a recovery of the 


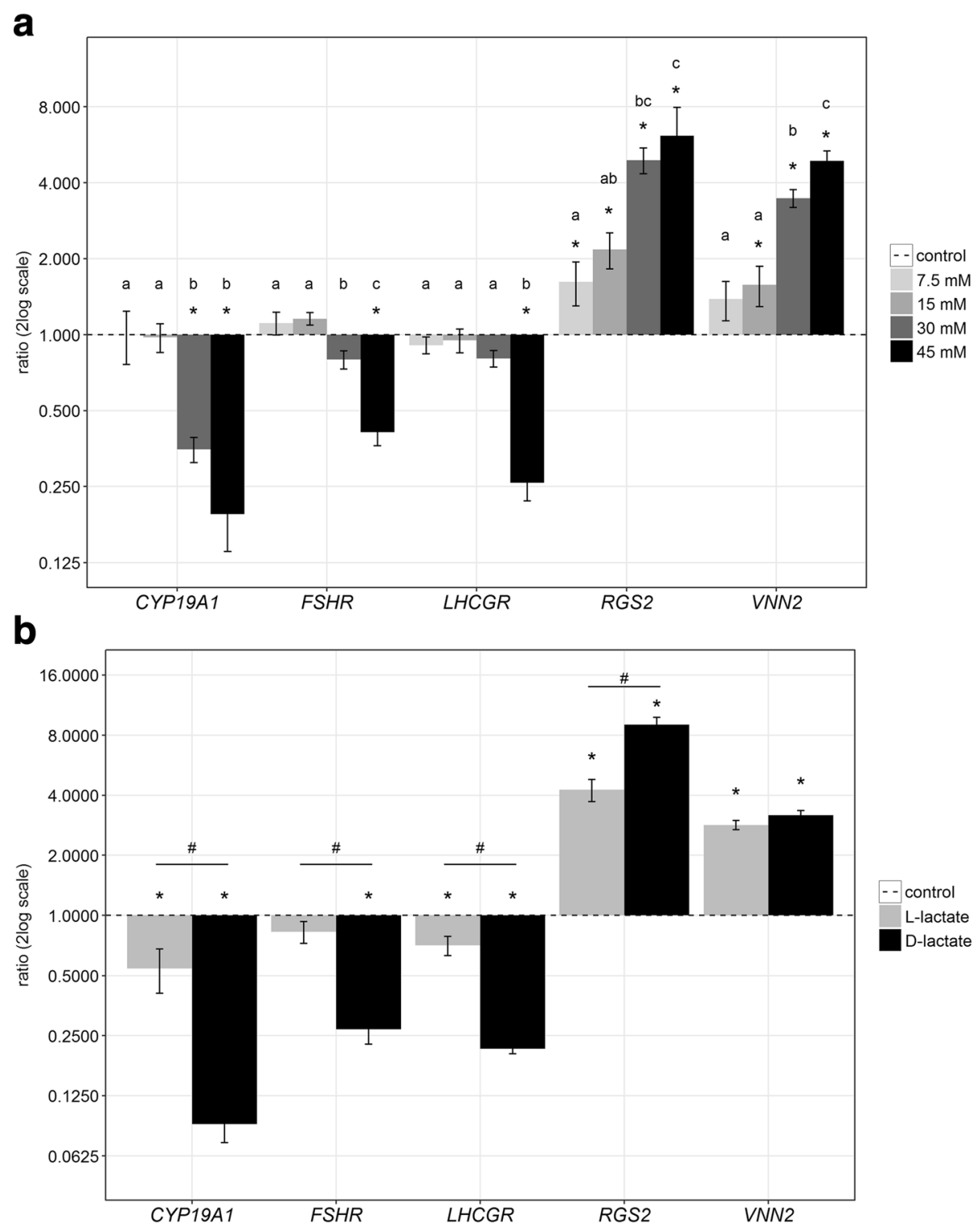

Fig. 1 Effects of different L-lactate concentrations and of the steric enantiomer D-lactate on cultured bovine GC. (a) Increasing L-lactate concentrations progressively decreased or increased the abundance of selected marker gene transcripts. Transcript abundance was normalized to RPLPO as a reference gene. The values (means \pm SEM) are shown as ratio relatively to the vehicle control (dashed line). For statistical testing of the L-lactate effect the RPLPOnormalized values were compared using the student $t$-test or Mann-Whitney test, $n=3,{ }^{*} P<0.05$. To test for effects of increasing L-lactate concentration an ANOVA was performed and letters indicate significant differences between treatment groups, $n=3, P<0.05$. (b) The supplementation with D-lactate (30 mM) elicited more prominent effects on gene expression than L-lactate $(30 \mathrm{mM})$ compared to the vehicle control (dashed line). The student's $t$-test or Mann-Whitney test was used for analyzing the $\mathrm{L}$ - and D-lactate effects compared to the respective control $\left(^{*}\right)$ and between $\mathrm{L}$ - and D-lactate treatment $(\#)$, $n=3, P<0.05$

Table 2 Effects of lactate and $\mathrm{NaCl}$ control on the viability of cultured bovine GC

\begin{tabular}{llll}
\hline treatment & untreated & lactate & $\mathrm{NaCl}$ \\
\hline OD & 0.997 & 0.640 & 1.291 \\
SEM & 0.245 & 0.177 & 0.165
\end{tabular}

The cells were cultured for 8 days under serum-free, E2-active conditions, with L-lactate or the vehicle control $\mathrm{NaCl}$ (both $30 \mathrm{mM}$ ) supplementation. The mean OD (optical density) of $n=4$ replicates is shown with SEM (standard error of means), no significant differences between treatment groups were observed, $P=0.108$ (ANOVA) transcript abundance levels of CYP19A1 and FSHR (Fig. 4b). Also in case of PTX3, RGS2 and VNN2 the L-lactate-induced increment was reduced, although the transcript abundance was still significantly higher than in the control, except for VNN2. The treatment with the inhibitor alone resulted in no obvious changes compared to the vehicle control. 

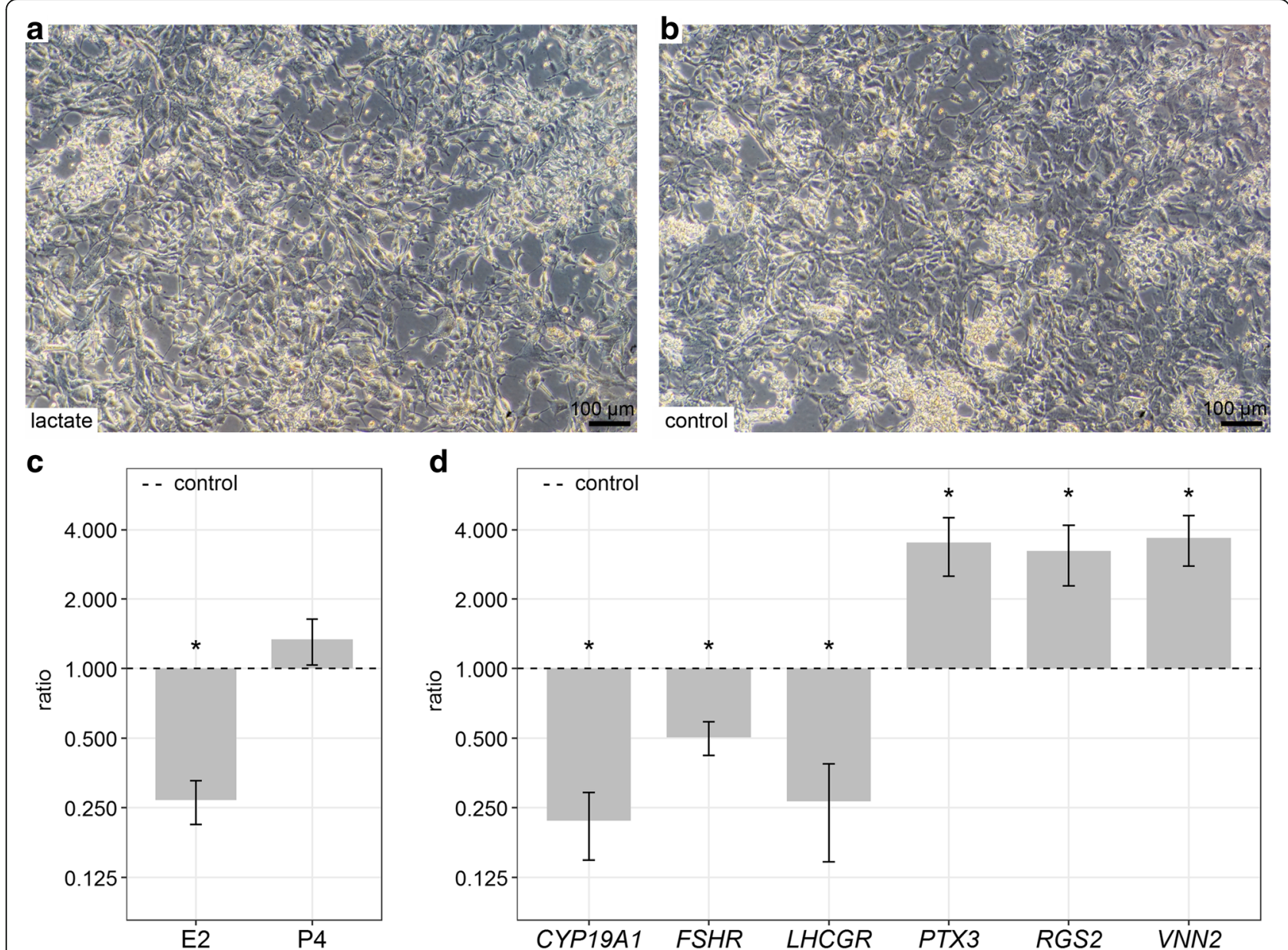

d

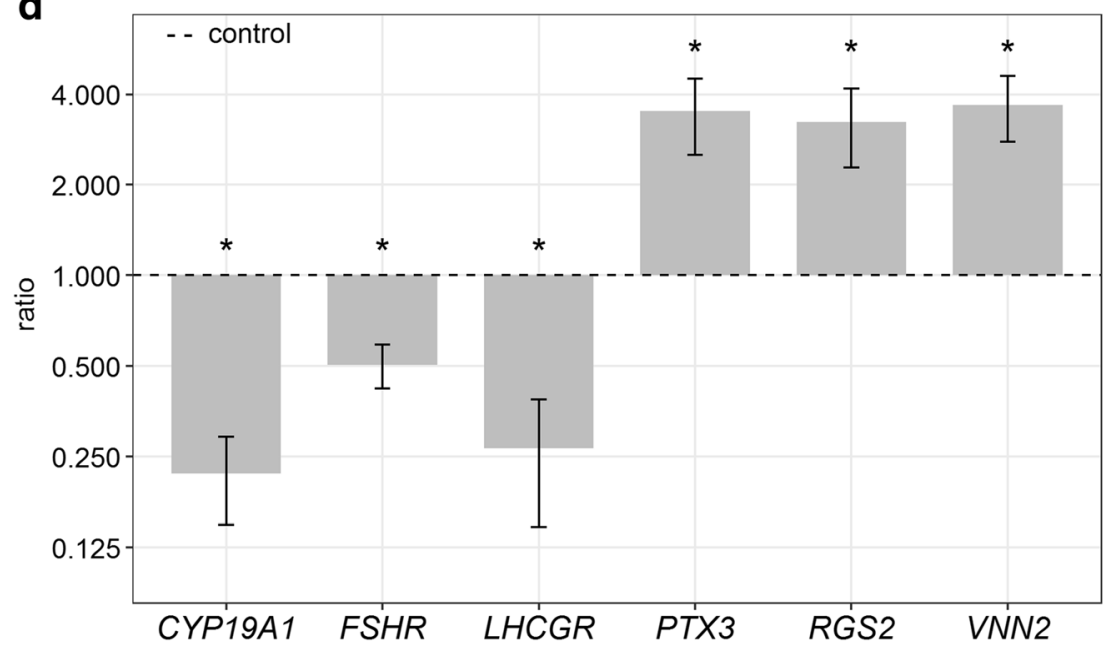

Fig. 2 Effects of L-lactate on the morphology, hormone concentration and gene expression. GC were cultured with L-lactate (30 mM) supplementation compared to the corresponding vehicle control in a standardized serum-free culture system for 8 days. (a-b) Cultured cells displayed a typical GC-like morphology and tended to form clusters. (c) Hormone profiles of L-lactate treated cells indicated relatively to the control (dashed line). The concentration of E2 (in $\mathrm{ng} / \mathrm{ml}$ ) was significantly decreased relative to the vehicle control (dashed line). (d) The expression of selected marker genes was specifically regulated in L-lactate treated cells as compared to the vehicle control (dashed line). The transcript abundance was normalized to the reference gene RPLPO. Means and SEM are shown of $n=3$ replicates, ${ }^{*} P<0.05$, student $t$-test or Mann-Whitney test.

\section{Effects of L-lactate and specific MCT inhibitor on genes related to L-lactate metabolism}

It was recently reported that L-lactate can influence genes related to the L-lactate metabolism resulting in a positive feedback mechanism [25]. Therefore, we were interested whether the genes encoding L-lactate dehydrogenase, $L D H A$, or L-lactate transporters, SLC16A1 and SLC16A7, were affected. The LDHA transcript abundance was strongly increased upon L-lactate treatment (Fig. 5), but also the L-lactate transporters SLC16A1 and SLC16A7 showed a significant upregulation. After pre-treatment with UK5099, the Llactate effects on the expression of $L D H A$ and SLC16A1 could be nearly reversed.

Table 3 Effects of short-term lactate treatment on gene expression of selected marker genes and steroid hormone production

\begin{tabular}{llllllll}
\hline Gene / hormone & CYP19A1 & FSHR & LHCGR & RGS2 & VNN2 & E2 & P4 \\
\hline Control & $3.12( \pm 0.31)$ & $34.70( \pm 4.41)$ & $3.29( \pm 0.46)$ & $5.56( \pm 0.29)$ & $6.26( \pm 0.39)$ & $23.72( \pm 1.57)$ & $824.61( \pm 84.99)$ \\
L-lactate & $3.78( \pm 0.85)$ & $49.10( \pm 8.33)$ & $3.18( \pm 0.94)$ & $5.78( \pm 0.32)$ & $7.39( \pm 1.11)$ & $32.31( \pm 5.26)$ & $905.01( \pm 47.03)$ \\
$P$ & 0.50 & 0.20 & 0.92 & 0.63 & 0.39 & 0.19 & 0.45 \\
\hline
\end{tabular}

GC were stimulated with $30 \mathrm{mM} \mathrm{L-lactate}$ or the vehicle control $\mathrm{NaCl} 24 \mathrm{~h}$ prior to the end of the culture period of 8 days. Transcript abundance $\left(\times 10^{-3}\right.$, normalized to the reference gene $R P L P O$ ) and hormone concentrations (in $\mathrm{ng} / \mathrm{ml}$ ) are shown as means $( \pm \mathrm{SEM})$ of $n=3$ replicates, $P$-values were calculated using the student's $t$-test or Mann-Whitney Test 


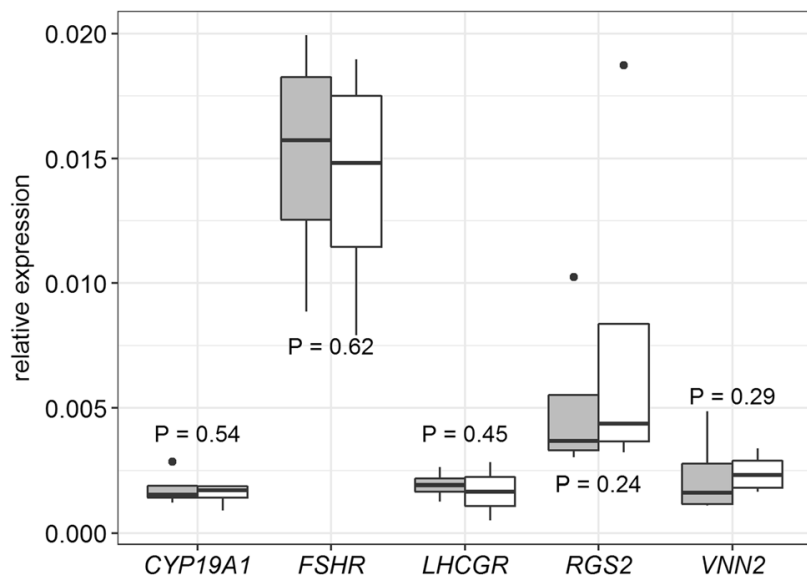

$$
\begin{aligned}
& \text { glucose } \\
& \text { concentration } \\
& \text { 帛 } 1 \mathrm{~g} / \mathrm{l} \\
& \text { 穴 } 4 \mathrm{~g} / \mathrm{l}
\end{aligned}
$$

Fig. 3 Effects of different glucose concentration in media. GC were cultured in basal media with $1 \mathrm{~g} / \mathrm{l}$ glucose (grey) or increased concentration of $4 \mathrm{~g} / \mathrm{l}$ glucose (black). No change in the expression of selected genes could be detected. Transcript abundance was normalized to reference gene RPLPO. Box plots with medians of $n=4$ replicates are shown; dots indicate outliers, student $t$-test or Mann-Whitney test with no statistical significance.

\section{Discussion}

Initial experiments with different lactate concentrations revealed significant effects on $R G S 2$ expression with $7.5 \mathrm{mM}$ and on CYP19A1 or FSHR expression with $30 \mathrm{mM}$. LHCGR was significantly affected only with $45 \mathrm{mM}$. However, this might be due to the generally observed greater variance of LHCGR, of which the very low abundance levels were close to the detection limit. Nonetheless, based on these data, an L-lactate concentration of $30 \mathrm{mM}$ was used as an effective concentration throughout the following experiments. Interestingly, the non-metabolized enantiomer D-lactate elicited more prominent effects on gene expression than L-lactate. An effect of D-lactate was also described by Latham et al. [35] and Wagner et al. [37], analyzing HDAC activity.
However, it must be considered that the concentrations of D-lactate in mammalian species has been shown to be three orders of magnitude lower than those of L-lactate [38], thus raising the question whether D-lactate plays any important role after all. But nonetheless, our data on increased effects of the non-metabolized D-lactate support our hypothesis that L-lactate can act as a signaling molecule apart from being metabolized. Moreover, it is reasonable that the enhanced effects of D-lactate are due to the non-metabolized status in mammalian cells. At this point we cannot exclude the possibility that a part of Llactate is metabolized, which in turn leads to a reduction of L-lactate concentration and hence results in minor effects than the non-metabolized D-lactate. This leads to the suggestion that chirality might not be the primary a

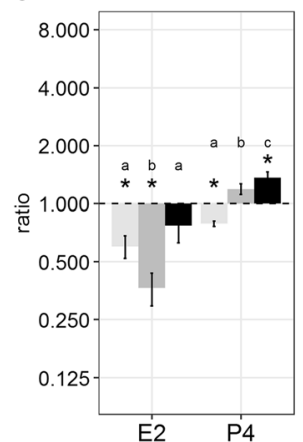

b

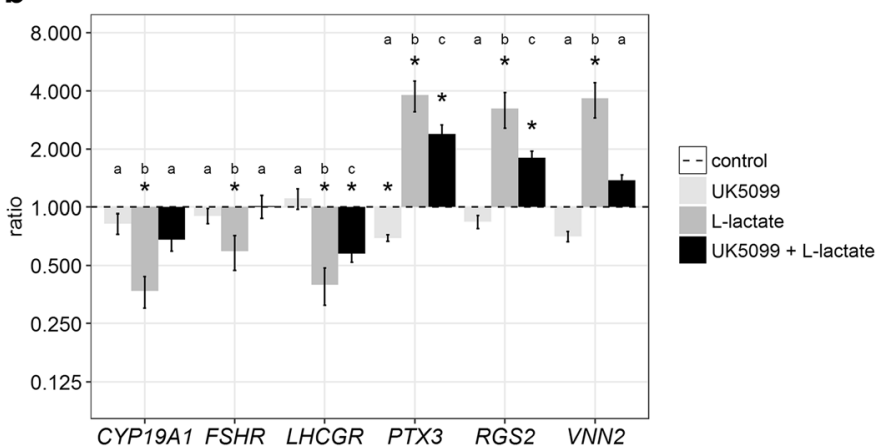

Fig. 4 Effects of L-lactate transport inhibitors on L-lactate induced changes of hormone and gene expression profile. GC were cultured as described before and additionally pre-treated for two days with the inhibitor for L-lactate transporters, UK5099 (50 $\mu \mathrm{M})$. (a) Inhibition of L-lactate transporters (black bars) resulted in the reversal of the L-lactate effect (dark grey bars) on E2 production. (b) The gene expression levels of selected transcripts nearly regained control levels (dashed line) after inhibition of L-lactate transporters, whereas the inhibitor alone showed nearly no effects (light grey bars). Transcript abundance was normalized to the reference gene RPLPO. Means and SEM of the hormone concentration and gene expression are shown of $n=4$ replicates. The student's $t$-test or Mann-Whitney test was used for analyzing the effects compared to the vehicle control $\left(^{*}\right)$ and between different treatments the ANOVA testing was used (indicated by letters), $n=4, P<0.05$. 


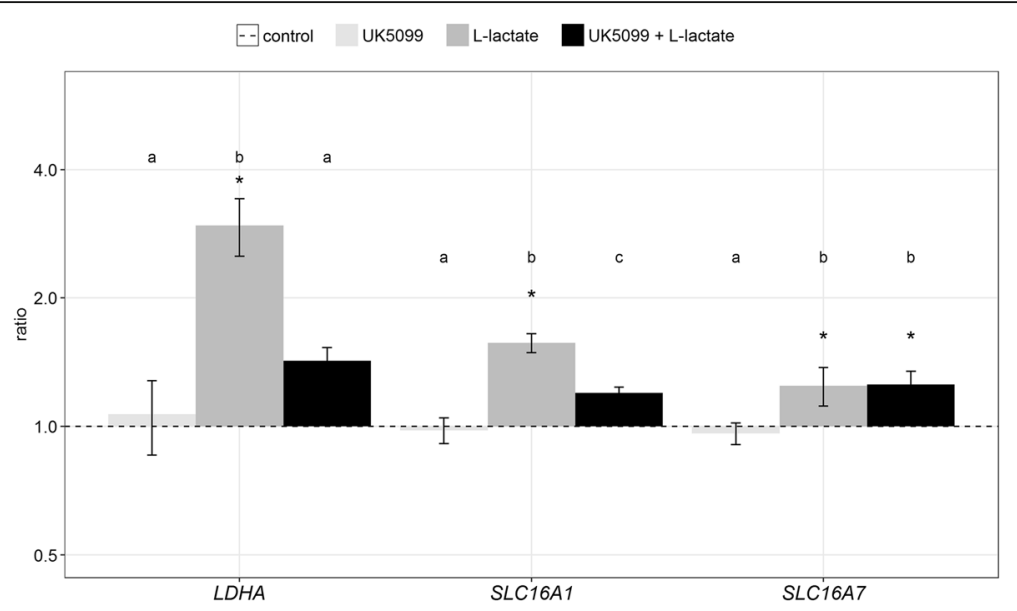

Fig. 5 Effect of L-lactate and specific inhibitor of L-lactate transport on genes involved in L-lactate metabolism. The abundance of LDHA and SLC16A1 transcripts was up-regulated in L-lactate treated GC (grey bars) compared to the control (dashed line; *). When the cells were pre-incubated with the inhibitors UK5099 the L-lactate induced changes of expression levels were largely abolished. No effect was observed with the inhibitor alone (light grey bars). Transcript abundance was normalized to RPLPO as a reference gene. Means and SEM are shown of $n=4$ replicates, ${ }^{*} P<0.05$, student's $t$-test or Mann-Whitney test was uses to test treatment effects compared to the vehicle control $\left(^{*}\right)$ and between different treatments the ANOVA was used (indicated by letters).

parameter for signaling efficiency. This hypothesis has to be further taken into account in subsequent studies.

Interestingly, our results of different glucose concentration in GC media revealed no alterations in the gene expression. This indicates that an increased energy supply and thus higher metabolic activity alone is not sufficient to induce differentiation of bovine GCs in culture, which was shown in a previous work in sheep GC [39].

In follicular fluids of rats L-lactate concentrations of $27 \mathrm{mM}$ had been detected at the time of the expected LH surge, when the serum concentration of L-lactate remained considerably low at $5 \mathrm{mM}$ [21]. Studies in humans showed concentrations of $6.2 \mathrm{mM}$ L-lactate at the time of oocyte recovery from women undergoing IVF [19]. In the bovine different values have been reported ranging from $5 \mathrm{mM}$ up to $14.4 \mathrm{mM}$ depending on the size or stage of the follicle [20, 40,41]. Until now, effects of L-lactate on the cell physiology and gene expression have been only studied in rat L6 cells, human mesenchymal stem cells, human HCT116 cells or mouse neurons, where effective concentrations ranged from 10 to $30 \mathrm{mM}$ lactate $[27,34,35,42]$. To our knowledge the present study is the first one that aims at clarifying the effects of L-lactate on GC differentiation in any species.

Short-term treatment of cultured bovine GC at the end of the culture period did not lead to considerable alterations. Neither hormone production nor gene expression profiles were significantly affected. Interestingly, this observation is in line with a conclusion by others that short-term exposure to L-lactate does not affect gene expression, but may already have some effects on the cell metabolism [23]. Furthermore, it was suggested that effects on gene expression potentially require longterm exposure to L-lactate [23]. This is clearly supported by our data showing that only long-term treatment could induce significant changes of physiological and molecular parameters in cultured GC, although the typical GC-like morphology and formation of cell clusters $[13,30,32]$ was not affected by L-lactate. Estradiol production clearly decreased whereas progesterone production was nearly unaffected compared to the controls. Estradiol down-regulation can be easily attributed to the remarkable down-regulation of the aromatase coding gene CYP19A1. Besides CYP19A1 we also analyzed additional marker genes of an early LH-dependent differentiation, which have been shown to be highly regulated following the pre-ovulatory LH-surge in vivo $[4,5,7]$. In particular, FSHR and LHCGR were found downregulated and RGS2, VNN2 and PTX3 clearly upregulated upon L-lactate treatment. These data together with the alterations of the hormone production suggest that L-lactate can induce a stage of differentiation in cultured GC that is similar to the early post-LH stage in vivo. Previous studies identified increased L-lactate concentrations after hCG stimulation in human GC culture or in the antral fluid of follicles in macaques thus supporting our conclusion [43, 44]. L-lactate is well known as a product of anaerobic respiration, but may also play a role as regulatory molecule even during adequate oxygen provision [22, 24]. Interestingly, it was described in several studies that L-lactate can act as a signaling molecule in fibroblasts [45], macrophages [46] and even neuronal cells $[27,28]$. Yang and colleagues showed that in neurons L-lactate affected the expression of genes 
involved in the establishment of long-term memory [27]. In another recent study L-lactate exhibited neuroprotective properties against excitotoxicity by coordinating specific cellular pathways [47]. The results of our study indicate for the first time a specific role of L-lactate as a signaling molecule in bovine GC.

As a next approach we tested if L-lactate uptake is an essential prerequisite to induce the observed effects. The inhibition of L-lactate uptake was accomplished with UK5099, a potent MCT inhibitor of L-lactate transport [27]. This inhibitor is characterized to target the group of MCT 1-4 that are responsible for lactate as well as pyruvate transport. Accordingly, the transport of Llactate into the cells should be completely inhibited by UK5099. Our results showed that the estradiol concentrations as well as the expression of selected marker genes nearly regained control levels after inhibiting the MCTs. This clearly suggests that the observed effects are vitally dependent upon L-lactate uptake into GC. It has been shown in neurons, that transport of L-lactate into the cells and $\mathrm{K}_{\mathrm{ATP}}$ channels [48] or NMDA receptor activation [27] is necessary to promote the observed changes. In contrast to our data demonstrating strong effects of the non-metabolized D-lactate, the conversion of L-lactate to pyruvate is a crucial prerequisite in both cases. Whereas the rise of ATP production is essential for $\mathrm{K}_{\mathrm{ATP}}$ channel actions, the increase in the NADH/ NAD ratio leads to the modulation of NMDA receptor activity [28]. Here we can only speculate on mechanisms occurring in bovine GC. But in human ovaries functional ATP-sensitive potassium channels could be identified and moreover it was shown that blocking of these ion channels negatively influences progesterone production [49]. In ovarian tissue and granulosa cells expression of specific subunits of the NMDA receptor, the subunits 1 and 2B, had been identified [50] thus supporting the view that this receptor might be involved in these cells as well. Expression of NMDAR subunits, especially of GRIN2D and GRINA has been found in vivo in GC (see database GranulosaIMAGE [51]) as well as in vitro (own GC culture microarray dataset [14]). Whether these receptor subunits can actually form functional receptors to be modulated by L-lactate in bovine GC has to be investigated in further studies. However, our data clearly show that L-lactate uptake is mandatory for most of the observed effects thus excluding the possibility that a G-protein coupled receptor for lactate, coded by HCAR1, might be necessary to carry the L-lactate signal across the cell membrane [52]. In addition, HCAR1 transcripts were not detectable in our GC culture system (data not shown) thus indicating that HCAR1 is not expressed in cultured GC. This is further supported by in vivo data demonstrating that HCAR1 expression could not be detected in GC [51]. The mode of action of
L-lactate within bovine GC, however, is still an open question and has to be further elucidated.

At present, we cannot completely exclude the possibility that endogenous L-lactate production by the cultured cells might contribute to the observed effects. However, in an initial study without any lactate treatment we measured lactate concentrations in the media of approximately $7 \mathrm{mM}$ (not shown), which is far from the effective concentrations used during the presented study. Therefore, it is reasonable to assume that endogenously produced lactate did not significantly interfere with our experimental settings.

The present results demonstrate that L-lactate has positive effects on the expression of $L D H A$, the enzyme regulating the L-lactate-pyruvate-ratio as well as on the expression of its transporters, SLC16A1 and SLC16A7. This is in accordance with earlier observations by others that L-lactate directly stimulates the expression of the MCT1 protein (encoded by SLC16A1) in L6 cells [34]. Another study showed that endurance training, leading to a higher L-lactate production, increased MCT1 expression in rats and humans [23]. This suggests that also in bovine GC L-lactate can stimulate its own metabolism and transport, thus being part of a positive feedback loop. Supportively, in skeletal muscle cells it was shown that MCT1 expression and L-lactate uptake is dependent on the activation of PKA and PKC signaling [53]. This is an interesting hypothesis, having in mind that the PKA signaling is one pathway involved in inducing luteinization of GC [54].

\section{Conclusions}

The presented data on hormone production and expression of marker genes clearly suggest that L-lactate treatment of cultured bovine $\mathrm{GC}$ results in a differentiation similar to early LH-induced alterations in vivo. Furthermore, the data suggest that L-lactate is involved in a positive feedback mechanism regulating its own transport and metabolism. The accumulation of L-lactate within the follicular fluid [19-21, 40] suggests that Llactate also plays a role in vivo as a differentiation factor during late folliculogenesis and the folliculo-luteal transition in monovular species. In subsequent studies this hypothesis of the impact of lactate on GC differentiation has to be proven in in vivo models as well.

\section{Additional file}

\footnotetext{
Additional file 1: Figure S1. Comparison of the expression of marker genes in GC cultured immediately after isolation vs. GC cultured after cryo-preservation. No difference between GC cultured either directly after isolation or after cryo-preservation could be observed. Transcript abundance is shown as absolute expression (copy number per $\mu \mathrm{g}$ RNA) of $n=3$, student's t-test revealed no significant differences. (TIFF $226 \mathrm{~kb}$ )
} 


\section{Abbreviations}

BSA: Bovine serum albumin; CV: Coefficient of variation; CYP19A1: Aromatase; DMSO: Dimethyl sulfoxide; E2: Estradiol; FSH: Follicle stimulating hormone; FSHR: FSH receptor; GC: Granulosa cells; GRIN2D: Glutamate ionotropic receptor NMDA type subunit 2D; GRINA: Glutamate ionotropic receptor NMDA type subunit associated protein 1; HCAR1: Hydroxycarboxylic acid receptor 1; hCG: Human choriogonadotropin; HDAC: Histone deacetylase; HIF1/ 2a: hypoxia-inducible factors $1 / 2$ alpha; IGF-1: Insulin-like growth factor 1; LDHA: Lactate dehydrogenase; LH: Luteinizing hormone; LHCGR: LH/ choriogonadotropin receptor; MCT: Monocarboxylate transporter; MEM: Minimal essential media; NMDAR: N-methyl-D-aspartate receptor; P4: Progesterone; PBS: Phosphate buffered saline; PKA: Protein kinase A; PKC: Protein kinase C; PTX3: Pentraxin 3; qPCR: quantitative PCR; RIA: Radioimmunoassay; RGS2: Regulator of G protein signaling 2; SLC16A1: Solute carrier family 16 member 1; SLC16A7: Solute carrier family 16 member 7; UK5099: 2-Cyano-3-(1-phenyl-1Hindol-3-yl)-2-propenoic acid; VNN2: Vanin 2

\section{Acknowledgments}

We thank Veronica Schreiter and Maren Anders for excellent technical assistance.

\section{Funding}

This study was funded by the core budget of the Leibniz Institute for Farm Animal Biology (FBN).

\section{Availability of data and materials}

The datasets used and/or analysed during the current study are available from the corresponding author on reasonable request.

\section{Authors' Contributions}

A.B. executed and analyzed the data, wrote the manuscript draft and created the figures; J.V. designed the study, analyzed data and contributed to the final version of the manuscript. Both authors read and approved the final manuscript.

\section{Ethics approval}

Not applicable.

\section{Consent for publication}

Not applicable.

\section{Competing interests}

The authors declare that there is no conflict of interest that could be perceived as prejudicing the impartiality of the research reported.

\section{Publisher's Note}

Springer Nature remains neutral with regard to jurisdictional claims in published maps and institutional affiliations.

Received: 20 December 2017 Accepted: 15 February 2018 Published online: 20 February 2018

\section{References}

1. Bao B, Garverick HA. Expression of steroidogenic enzyme and gonadotropin receptor genes in bovine follicles during ovarian follicular waves: a review. J Anim Sci. 1998;76:1903-21.

2. Adams GP, Jaiswal $R$, Singh J, Malhi P. Progress in understanding ovarian follicular dynamics in cattle. Theriogenology. 2008;69:72-80.

3. Gilbert I, Robert C, Dieleman S, Blondin P, Sirard MA. Transcriptional effect of the $\mathrm{LH}$ surge in bovine granulosa cells during the peri-ovulation period. Reproduction. 2011;141:193-205.

4. Christenson LK, Gunewardena S, Hong X, Spitschak M, Baufeld A, Vanselow J. Research resource: preovulatory LH surge effects on follicular theca and granulosa transcriptomes. Mol Endocrinol. 2013;27:1153-71.

5. Nimz M, Spitschak M, Schneider F, Fürbass R, Vanselow J. Down-regulation of genes encoding steroidogenic enzymes and hormone receptors in late preovulatory follicles of the cow coincides with an accumulation of intrafollicular steroids. Domest Anim Endocrinol. 2009:37:45-54.

6. Bao B, Garverick HA, Smith GW, Smith MF, Salfen BE, Youngquist RS. Changes in messenger ribonucleic acid encoding luteinizing hormone receptor, cytochrome P450 side chain cleavage, and aromatase are associated with recruitment and selection of bovine ovarian follicles. Biol Reprod. 1997:56:1158-68.

7. Ujioka T, Russell DL, Okamura H, Richards JS, Espey LL. Expression of regulator of G-protein signaling protein-2 gene in the rat ovary at the time of ovulation. Biol Reprod. 2000;63:1513-7.

8. Varani S, Elvin JA, Yan C, DeMayo J, DeMayo FJ, Horton HF, Byrne MC, Matzuk MM. Knockout of pentraxin 3, a downstream target of growth differentiation factor-9, causes female subfertility. Mol Endocrinol. 2002; 16:1154-67.

9. Fadhillah YS, Nishimura R, Okuda K. Hypoxia promotes progesterone synthesis during luteinization in bovine granulosa cells. J Reprod Dev. 2014;60:194-201.

10. Kim J, Bagchi IC, Bagchi MK. Signaling by hypoxia-inducible factors is critical for ovulation in mice. Endocrinology. 2009;150:3392-400.

11. Thompson JG, Brown HM, Kind KL, Russell DL. The ovarian antral follicle: living on the edge of hypoxia or not? Biol Reprod. 2015:92:153.

12. Marsters $P$, Alhamdan R, Campbell BK. Cell density-mediated pericellular hypoxia and the local dynamic regulation of VEGF-a splice variants in ovine ovarian granulosa cells. Biol Reprod. 2014;91:35.

13. Baufeld A, Vanselow J. Increasing cell plating density mimics an early postLH stage in cultured bovine granulosa cells. Cell Tissue Res. 2013;354:869-80.

14. Baufeld A, Koczan D, Vanselow J. Induction of altered gene expression profiles in cultured bovine granulosa cells at high cell density. Reprod Biol Endocrinol. 2017;15:3.

15. Cui XG, Han ZT, He SH, Wu XD, Chen TR, Shao CH, Chen DL, Su N, Chen YM, Wang T, et al. HIF1/2alpha mediates hypoxia-induced LDHA expression in human pancreatic cancer cells. Oncotarget. 2017;8:24840-52.

16. Firth JD, Ebert BL, Ratcliffe PJ. Hypoxic regulation of lactate dehydrogenase a. Interaction between hypoxia-inducible factor 1 and cAMP response elements. J Biol Chem. 1995;270:21021-7.

17. Semenza GL, Jiang BH, Leung SW, Passantino R, Concordet JP, Maire P, Giallongo A. Hypoxia response elements in the aldolase a, enolase 1, and lactate dehydrogenase a gene promoters contain essential binding sites for hypoxia-inducible factor 1. J Biol Chem. 1996;271:32529-37.

18. Lee DC, Sohn HA, Park ZY, Oh S, Kang YK, Lee KM, Kang M, Jang YJ, Yang SJ, Hong YK, et al. A lactate-induced response to hypoxia. Cell. 2015;161: 595-609.

19. Leese HJ, Lenton EA. Glucose and lactate in human follicular fluid: concentrations and interrelationships. Hum Reprod. 1990;5:915-9.

20. Leroy JL, Vanholder T, Delanghe JR, Opsomer G, Van SA, Bols PE, de Kruif A. Metabolite and ionic composition of follicular fluid from different-sized follicles and their relationship to serum concentrations in dairy cows. Anim Reprod Sci. 2004;80:201-11.

21. Zeilmaker $\mathrm{GH}$, Verhamme CM. Lactate concentrations in pre-ovulatory follicles of pro-oestrous rats before and after onset of oocyte maturation. Acta Endocrinol. 1977;86:380-3.

22. Philp A, Macdonald AL, Watt PW. Lactate-a signal coordinating cell and systemic function. J Exp Biol. 2005;208:4561-75.

23. Brooks GA. Cell-cell and intracellular lactate shuttles. J Physiol. 2009;587: 5591-600.

24. Brooks GA. Lactate shuttles in nature. Biochem Soc Trans. 2002;30:258-64.

25. Hashimoto T, Masuda S, Taguchi S, Brooks GA. Immunohistochemical analysis of MCT1, MCT2 and MCT4 expression in rat plantaris muscle. J Physiol. 2005;567:121-9.

26. Kuchiiwa T, Nio-Kobayashi J, Takahashi-Iwanaga H, Yajima T, Iwanaga T. Cellular expression of monocarboxylate transporters in the female reproductive organ of mice: implications for the genital lactate shuttle. Histochem Cell Biol. 2011; 135:351-60.

27. Yang J, Ruchti E, Petit JM, Jourdain P, Grenningloh G, Allaman I, Magistretti PJ. Lactate promotes plasticity gene expression by potentiating NMDA signaling in neurons. Proc Natl Acad Sci U S A. 2014;111:12228-33.

28. Mosienko V, Teschemacher AG, Kasparov S. Is L-lactate a novel signaling molecule in the brain? J Cereb Blood Flow Metab. 2015;35:1069-75.

29. Silva JM, Price CA. Effect of follicle-stimulating hormone on steroid secretion and messenger ribonucleic acids encoding cytochromes P450 aromatase and cholesterol side-chain cleavage in bovine granulosa cells in vitro. Biol Reprod. 2000;62:186-91.

30. Gutierrez CG, Campbell BK, Webb R. Development of a long-term bovine granulosa cell culture system: induction and maintenance of estradiol production, response to follicle- stimulating hormone, and morphological characteristics. Biol Reprod. 1997;56:608-16.

31. Yenuganti VR, Vanselow J. Cultured bovine granulosa cells rapidly lose important features of their identity and functionality, but partially 
recover under long term culture conditions. Cell \& Tissue Research. 2017:368(2):397-403.

32. Hamel M, Vanselow J, Nicola ES, Price CA. Androstenedione increases cytochrome P450 aromatase messenger ribonucleic acid transcripts in non-luteinizing bovine granulosa cells. Mol Reprod Dev. 2005;70:175-83.

33. Yenuganti VR, Viergutz T, Vanselow J. Oleic acid induces specific alterations in the morphology, gene expression and steroid hormone production of cultured bovine granulosa cells. Gen Comp Endocrinol. 2016;232:134-44.

34. Hashimoto T, Hussien R, Oommen S, Gohil K, Brooks GA. Lactate sensitive transcription factor network in L6 cells: activation of MCT1 and mitochondrial biogenesis. FASEB J. 2007;21:2602-12.

35. Latham T, Mackay L, Sproul D, Karim M, Culley J, Harrison DJ, Hayward L, Langridge-Smith P, Gilbert N, Ramsahoye BH. Lactate, a product of glycolytic metabolism, inhibits histone deacetylase activity and promotes changes in gene expression. Nucleic Acids Res. 2012;40:4794-803.

36. Oh MS, Uribarri J, Alveranga D, Lazar I, Bazilinski N, Carroll HJ. Metabolic utilization and renal handling of D-lactate in men. Metabolism. 1985;34:621-5.

37. Wagner W, Ciszewski WM, Kania KD. L- and D-lactate enhance DNA repair and modulate the resistance of cervical carcinoma cells to anticancer drugs via histone deacetylase inhibition and hydroxycarboxylic acid receptor 1 activation. Cell Commun Signal. 2015;13:36.

38. Ewaschuk JB, Naylor JM, Zello GA. D-lactate in human and ruminant metabolism. J Nutr. 2005;135:1619-25.

39. Campbell BK, Onions V, Kendall NR, Guo L, Scaramuzzi RJ. The effect of monosaccharide sugars and pyruvate on the differentiation and metabolism of sheep granulosa cells in vitro. Reproduction. 2010;140:541-50.

40. Nishimoto H, Hamano S, Hill GA, Miyamoto A, Tetsuka M. Classification of bovine follicles based on the concentrations of steroids, glucose and lactate in follicular fluid and the status of accompanying follicles. J Reprod Dev. 2009:55:219-24

41. Orsi NM, Gopichandran N, Leese HJ, Picton HM, Harris SE. Fluctuations in bovine ovarian follicular fluid composition throughout the oestrous cycle. Reproduction. 2005;129:219-28.

42. Zieker D, Schafer R, Glatzle J, Nieselt K, Coerper S, Kluba T, Northoff H, Konigsrainer A, Hunt TK, Beckert S. Lactate modulates gene expression in human mesenchymal stem cells. Langenbeck's Arch Surg. 2008;393:297-301.

43. Richardson MC, Cameron IT, Simonis CD, Das MC, Hodge TE, Zhang J, Byrne $\mathrm{CD}$. Insulin and human chorionic gonadotropin cause a shift in the balance of sterol regulatory element-binding protein (SREBP) isoforms toward the SREBP-1C isoform in cultures of human granulosa cells. J Clin Endocrinol Metab. 2005;90:3738-46.

44. Brogan RS, MacGibeny M, Mix S, Thompson C, Puttabyatappa M, Vandevoort CA, Chaffin CL. Dynamics of intra-follicular glucose during luteinization of macaque ovarian follicles. Mol Cell Endocrinol. 2011;332:189-95.

45. Trabold O, Wagner S, Wicke C, Scheuenstuhl H, Hussain MZ, Rosen N, Seremetiev A, Becker HD, Hunt TK. Lactate and oxygen constitute a fundamental regulatory mechanism in wound healing. Wound Repair Regen. 2003;11:504-9.

46. Constant JS, Feng JJ, Zabel DD, Yuan H, Suh DY, Scheuenstuhl H, Hunt TK, Hussain MZ. Lactate elicits vascular endothelial growth factor from macrophages: a possible alternative to hypoxia. Wound Repair Regen. 2000;8:353-60.

47. Jourdain P, Allaman I, Rothenfusser K, Fiumelli H, Marquet P, Magistretti PJ. L-lactate protects neurons against excitotoxicity: implication of an ATPmediated signaling cascade. Sci Rep. 2016;6:21250.

48. Parsons MP, Hirasawa M. ATP-sensitive potassium channel-mediated lactate effect on orexin neurons: implications for brain energetics during arousal. J Neurosci. 2010;30:8061-70.

49. Kunz L, Richter JS, Mayerhofer A. The adenosine 5'-triphosphate-sensitive potassium channel in endocrine cells of the human ovary: role in membrane potential generation and steroidogenesis. J Clin Endocrinol Metab. 2006;91: 1950-5.

50. Tachibana N, Kinoshita M, Kametani F, Tanaka K, Une Y, Komatsu Y, Kobayashi Y, Ikeda S. Expression of $\mathrm{N}$-methyl-D-aspartate receptor subunits in the bovine ovum: ova as a potential source of autoantigens causing anti-NMDAR encephalitis. Tohoku J Exp Med. 2015;235:223-31.

51. Khan DR, Fournier E, Dufort I, Richard FJ, Singh J, Sirard MA. Meta-analysis of gene expression profiles in granulosa cells during folliculogenesis. Reproduction. 2016;151:R103-10.

52. Cai TQ, Ren N, Jin L, Cheng K, Kash S, Chen R, Wright SD, Taggart AK, Waters MG. Role of GPR81 in lactate-mediated reduction of adipose lipolysis. Biochem Biophys Res Commun. 2008;377:987-91.
53. Narumi K, Furugen A, Kobayashi M, Otake S, Itagaki S, Iseki K. Regulation of monocarboxylate transporter 1 in skeletal muscle cells by intracellular signaling pathways. Biol Pharm Bull. 2010;33:1568-73.

54. Morris JK, Richards JS. Luteinizing hormone induces prostaglandin endoperoxide synthase-2 and luteinization in vitro by A-kinase and C-kinase pathways. Endocrinology. 1995;136:1549-58.

\section{Submit your next manuscript to BioMed Central and we will help you at every step:}

- We accept pre-submission inquiries

- Our selector tool helps you to find the most relevant journal

- We provide round the clock customer support

- Convenient online submission

- Thorough peer review

- Inclusion in PubMed and all major indexing services

- Maximum visibility for your research

Submit your manuscript at www.biomedcentral.com/submit
C Biomed Central 